\title{
EFL Learners' Perceptions, Practices and Achievement with the Online Learning Program Tell Me More
}

\author{
George Gyamfi \& Panida Sukseemuang \\ Prince of Songkla University, Thailand
}

\begin{abstract}
The study examined EFL learners' perceptions, practices and achievement with the online language-learning program Tell Me More (TMM). A questionnaire and semistructured focus group interview were used for data collection. A sample of $340 \mathrm{EFL}$ learners were surveyed for their perceptions and practices; of them, 10 were further selected for an in-depth semi-structured focus group interview. Data on the learners' scores at four proficiency levels were analyzed for learners' achievement. The results indicated that the learners perceived TMM moderately useful and easy to use for learning English. With regard to learners' practices, they multitasked and sometimes left the program on to count the hours of use. The Pearson's correlation analysis revealed a positive correlation between learners' perception of the usefulness and ease of use of TMM. However, there was no correlation between learners' perceptions and practices. The analysis of learners' scores indicated an improvement in achievement for learners at the beginner and advanced proficiency levels, while learners at the intermediate and intermediate+ proficiency levels had a drop in their achievement. The findings do not only expand the knowledge base of learners' perceptions, practices, and achievement with computer-assisted language learning programs but also guide institutions on how to make effective use of educational technologies to improve learning practices and performance.
\end{abstract}

Keywords: Tell Me More; Perception; Self-regulated practices; Achievement; Online learning program.

\section{Introduction}

Learners have frequently been overwhelmed with changes in the use of specific technology for language learning. This has led to the constant adaptation of learning styles and preferences to utilize new forms of technology for instant and continuous interaction. Additionally, this affect learners' views on how useful and easy to learn through these specific technologies as well as their roles and responsibilities in the entire learning process and engagement patterns.

Though studies have reported the impact of specific technologies, some have reported that the efforts of instructors are not receiving the success it promised (Weston \& Bain, 2010). A number of reasons have been put forward for this. For example, Barr, (2016) opined that factors such as relevance, perceptions, and accessibility play a crucial role students' engagement with technology. Venkatesh, Croteau and Rabah (2014) also concluded that self-regulated strategies, interactive online learning environment and activities are critical in shaping learners perceptions of educational technologies. Van Zanten, Somogyi and Curro (2012) further confirmed that what 
determines the use of educational programs is its fulfillment of their learners' perceptions and educational needs.

However, what runs common throughout the factors are learners' perception of technology, its fulfillment of their needs and how their literary skills will improve in the interaction with the technology (Kennedy et al., 2008; Kvavik, 2005). What is clear here is that factors such as learners' perceptions of educational technologies and their interactions (practices) affect the outcome educational technologies promised. This means that there is a relationship between learners' perceptions of educational technologies and their practices and achievement are pivotal in ensuring success. These factors work hand in hand and may be difficult to separate. In relation to TMM, research on these factors have been scarcely examined. This has created a gap in the literature on how these factors work together to influence learners' use of TMM. Therefore, in order to fill the gap and provide further insight in a different context, there is the need to investigate EFL learners' perceptions, autonomous practices, and achievement with TMM. Below is a short description of TMM, a further explanation of how learners' perceptions along with autonomous practices emerge and intersect and a review of the previous research on TMM.

\section{Description of Tell Me More}

Tell Me More (TMM) is an asynchronous online learning system and one of the advanced selflearning tools that may have a comprehensive solution for language learning. A perceived benefit of TMM is its ability to tutor learners by exposing them to learning content of different activities to practice reading, speaking, listening, reading, grammar and writing. Additionally, TMM can provide learners with activities of interaction through speaking and standard activities of vocabulary and grammar, which has been structured around carefully designed authentic events. Most educational institutions use TMM to encourage access to English language outside the classroom.

According to Levy (1997), Tell Me More is an application that distinctly possess the potential role of giving meaning, controlling the process of learning, providing feedback and evaluating learning. Godwin-Jones (2010) further pointed out that the fast rate at which web language programming has developed has allowed online English language application developers such as Tell Me More to incorporate dimensions such as it interactive and audiovisual elements to make current versions sophisticated and meet the demands of the modern times. However, several empirical studies and theoretical reviews on Tell Me More program (Reeser, 2002; Lafford, 2004) revealed its complexities in relation to the graphics quality, the audio, video and photographic content, its speech recognition and visualization and the user-friendliness and usability of the environment.

Recent studies on specific educational technology, TMM (Espinosa, 2013; Nielson, 2011; Kuama \& Intharaksa, 2016; Perez, 2014; Yunus, Hasim, Embi, \& Lubis, 2010) have focused on users' perceptions of usefulness to facilitate learning and the originality of the materials and activities. All the participants in these studies perceived the program useful and easy to use to improve communication, grammatical and lexical skills. However, how they used the technology and its impact on their performance is yet to be investigated. 


\section{Theoretical Framework}

\section{Learner Perceptions and Autonomy}

Learners' perceptions is the process which gives the basis for understanding, learning and knowing or for motivating a particular action or reaction (Greenberg \& Baron, 2008). Davis (1989) explained that learners' perceptions consist of two cognitive beliefs; learners' perception of the usefulness of an object (PU), which is the degree to which a technology improves one's skill or output on a job and perception of the ease of use (PEU), which is the ability to use a technology with little or no difficulty. Davis (1989) posits that learners make decisions based on their impression of how they perceive each mode of learning. Therefore, learners' perception of online learning would make learners' approach learning with an attitude would enhance or undermine their effort to use certain resources. Learner autonomy, on the other hand, requires that learners control their learning process by adapting, re-adapting and optimizing their learning behavior in different learning situations. Autonomous learners are often motivated which results in effective learning outcomes through the provision of diverse opportunities for learning.

Gettinger and Seibert (2002), as cited in Spanjer et al., (2008), posited that learners' perception and autonomy are related. They opined that during learning time, learners self-regulate the learning process and practices to show their investment, commitment and whether or not they are benefitting from the task. These self-regulatory practices are any action that involves rehearsing a behavior or engaging in an activity repeatedly, for improvement or mastery purpose. According to Alotaibi, (2015) these actions are influenced by learners' perceptions. Alotaibi, (2015) further posited that the link between learners' perceptions and practices is direct in that learners' practices are reflections of their perceptions of how the technology fulfills their needs, interest, preferences and performance

Results of the study by Artelt, Baumert, Julius-McElvany and Peschar, (2003) also give evidence to the effect that learners' autonomous practices and learning outcomes are connected. Additionally, according to Ainley and Patrick (2006), the link between perception and practices results from learners' self-regulated thoughts, feelings and behaviors, which were directed towards the acquisition of one's personal learning objectives. Overall, the intersection of these constructs determines whether learners will make use of appropriate or inappropriate practices while on a learning task in the program. For instance, Ulitsky (2000) study on the educational technology related to French in action and video series "Destinos" bares credence to this. The study generally revealed that learners' perceptions of their digital literacy and usefulness of the technologies drove them further to adopt practices such as using outside materials to support the program.

Furthermore, Coklar, (2012) posited that the convergence of learners' perceptions and practices is pivotal to our understanding of the effective utilization of computer learning programs for successful learner outcomes. Hence, perception, practices and achievement share an attributive relation. This relationship refutes the notion that learning outcomes have a fixed cause such the difficulty of the task or learner ability. The similarities between the goals of learner practices and perception is also striking as each adopt a realistic goal setting, planning, persuading learners to 
be responsible and encouraging the feeling of personal cause and self-confidence (Knowles, 1975).

In sum, the explanation of the concepts above has shown how relevant they are in language learning. These factors regulate learners' to use educational technologies in ways that may hinder or enhance the use of educational technologies.

\section{Prior Studies on Tell Me More}

There has been a considerable expansion on literature on Computer Assisted Language Learning (CALL). However, with regard to Tell Me More, the literature has retained limited focus either learners' perceptions, effectiveness or its utilization in improving specific language skills (Espinosa, 2013; Gyamfi \& Sukseemuang, 2017; Perez, 2014). These studies have been done to the disadvantage of aspects such as learners' perceptions, how learners use the program (practices), the relationship between perceptions and practices and their overall achievement across different proficiency levels.

For instance, Gyamfi and Sukseemuang (2017) study on the factors affecting EFL learners' use of Tell Me More did not only reveal learners' moderate perception about the usefulness and ease of use of the program but also learners' perception that TMM was more useful for improving their pre-communication skills. Although the respondents admitted that the program increased their interest in improving their language through the program, they felt unsatisfied with some aspects of TMM. What this study does not capture is the insight on how the learners used the program that accounted for the increased interest and dissatisfaction with the program. What is also lacking is the effect the program had on their overall performance in their use of the program.

Like the study above, Espinosa (2013) study revealed a similar finding in the perceptions of users of Tell Me More in the University of Malaga among teachers who used the program for six months. Specifically, the findings showed a moderate to low interest in terms of TMM's ability to improve users' instant communication skills, usefulness and effectiveness in improving language skills. The study further showed that the program suited some users' learning styles and preferences. This study widens the gap and calls for the need to investigate the effectiveness of TMM in relation to learners' achievement and the manner in which learners used the program to improve their language.

Perez (2014) study on University students in Philippines on the effectiveness of TMM in improving their communication skills revealed an interesting result. The participants of the study reported that they did not encounter any difficulties while using the program. However, a study by Nielson (2011) on the use of TMM and Rosetta Stone for self-study, revealed that despite the ease of access to the program, the learners encountered technological problems with the program and did not have enough support for their self-study. Even though both research were conducted in different contexts, what remains clear is the inconsistency in the findings. This strengthens the call for further studies on TMM in yet another different context for more insight on the program.

Even though studies have been carried out on these concepts in CALL, there is still more to be known about what learners' autonomous practices and perceptions of how TMM is usefulness 
and ease of use. This is because research on Tell Me More are insufficient and not generalizable given the characteristics of participants in terms of number, context, training, perception, proficiency, learning goals and motivation in learning English. Specifically, studies on TMM have been conducted in countries where English is used as a second language, for example Malaysia and the Philippines. Learners in such a setting may perceive and use educational technologies differently from those who study in a foreign language context like Thailand.

What is further missing from the literature on TMM is learners' overall learning achievement or outcomes after using the program. None of the studies reviewed above investigated learners' achievement with TMM. This, therefore, calls for further research on TMM to provide insight on how it is serving the needs of students. This has created a gap in the body of research and it has motivated the call for further research on learners' perception, practices and their achievement with Tell Me More.

\section{Research Questions}

1. What are learners' perceptions of the usefulness and ease of use of the Tell Me More program?

2. What are learners' practices when they use the Tell Me More program?

3. Is there any relationship between learners' perceptions and practices with TMM?

4. What effect does Tell Me More have on the language achievement of learner in different proficiency groups?

\section{Research Model}

\section{The Study}

This research used the mixed methodological approach in this study. This strategy was used because according to Creswell, Clark, Gutmann and Hanson (2003), it allows researchers to simultaneously collect data, concurrently analyze the data to confirm findings in relation to the impressions and opinions of respondents of a study. The researcher used a questionnaire to survey learners' perceptions and practices of TMM. A semi-structured focus group interview was conducted for an in-depth examination into that learners' perceptions and practices with specific aspects of the TMM program. Since the questionnaires elicited data without any explanations, the semi structured focus group interview augmented the findings by providing a richer and a more precise date for inferences to be made.

\section{Participants}

The population for the study were 2,137 first year University students in the south of Thailand who used the Tell Me More program in the Academic Year 2015. The population had fulfilled all the requirements for using the TMM program for the 2015 Academic Year as follows: 1 . Students who had completed the placement, progress and achievement tests in Tell Me More. 2. Students who used the program for the required number of hours based on their proficiency levels. The beginners used TMM for 50 hours, students at the intermediate and intermediate+ proficiency level used it for 40 and 30 hours respectively and the advanced level students used the program for 20 hours. Using Krejcie \& Morgan, (1970) technique, a sample of 350 were randomly selected 
for a survey. Based on the responses from the survey, ten (10) participants were purposively selected from a different proficiency levels and faculties to form a heterogeneous group for a semi-structured focus group interview.

\section{Instruments}

\section{Questionnaire}

The questionnaire for the study was divided into three sections. The first section elicited the demographics of the participant (Gender, student number, faculty, phone number/email, proficiency level). The second section had two sub-sections which focused on learners' perception of the usefulness and ease of use of TMM. The items in this section was adapted from the Technology Acceptance Model (TAM) (Davis, 1989). All the items in section 2 were adapted to suit the research context. This section used a five point Likert scale which ranged from strongly disagree (1) and strongly agree (5) to measure learners' perceptions. The third section surveyed learners' practices with TMM. The items in this section were adapted from the Effort and Persistence in Learning (EPL) with subscales of student approaches to learning survey (Artelt, Baumert, Julius-McElvany, \& Peschar, 2003). This section had a four-item Likert scale that ranged from almost never (1) to almost always (4). The interpretation for the 5-item and the 4-item Likert scale, which was adapted from Phongwichai (2008) are as follows:

Table 1. Interpretation for the 4-item Likert Scale for the Construct of Students' Practices

\begin{tabular}{lll}
\hline Interpretation & Practices & Mean Range \\
\hline Very low & Almost never & $1.00-1.75$ \\
\hline Low & Sometimes & $1.76-2.51$ \\
\hline High & Often & $2.52-3.27$ \\
\hline Very high & Always & $3.28-4.00$ \\
\hline
\end{tabular}

Table 2. Interpretation for the 5-item Likert Scale for the Constructs Perceptions.

\begin{tabular}{lll}
\hline Interpretation & Perception & Mean range \\
\hline Very low & Strongly disagree & 1.00 to 1.80 \\
\hline Low & Disagree & 1.81 to 2.60 \\
\hline Medium & N/A & 2.61 to 3.40 \\
\hline High & Agree & 3.41 to 4.20 \\
\hline Very high & Strongly agree & 4.21 to 5.00 \\
\hline
\end{tabular}

\section{Semi-Structured Focus Group Interview}

The semi structured focus group interview was done to examine students' in-depth perception, and practices. The items for the interview were developed based on the responses from the 
survey. Other items were generated from Technology Acceptance Model (TAM) (Davis, 1989) and Artelt, Baumert, Julius-McElvany, \& Peschar (2003) and were further adapted to suit the research context. The data from the focus group session helped the researcher triangulate the findings from the questionnaire to answer the research questions appropriately. The responses elicited from using this technique complemented the limited amount of information which the researcher got from the questionnaire for richer and more precise inferences.

\section{Measuring Learners' Achievement}

The placement, progress and achievement tests integrated in the full TMM learning program were used to measure learners' achievement. The students did placement test to show whether they fall under the beginner, intermediate, intermediate+ and advanced proficiency level. The progress test determined the learners' progress in the course of using the program. Finally, the achievement test evaluated learners; improvement after they have completed the course based on specific hours of use. The placement and progress tests were scored 10 points and were at a similar level of difficulty. However, the achievement test was scored out of 800 points and was at a higher level of difficulty. The level of difficulty and content of the achievement test was comparable to standardized tests like Test of English for International Communication (TOEIC). The TMM administrators tracked the learners' placement, progress, achievement tests scores and the hours of use. The scores for the entire population $(n=2,137)$ was analyzed to find the effectiveness of the TMM program. This was done to find the overall achievement of students who completed the full TMM course. However, the result the survey and the analysis of the entire population for learners' achievement could not be correlated due to the difference in the sample. In other words, the findings from the achievement test of the TMM program could not be related to the responses from the survey.

\section{Validity and Reliability}

The questionnaire, which was originally written in English, was translated into Thai by a bilingual expert. To make the items valid and reliable, a committee of experts in language, instructional technology and education reviewed the Thai and English versions to ensure its contents were credible and valid before piloting. Based on their reviews, some items both the English and Thai versions were modified to improve its clarity and consistency. After the compatibility checks, an approval was given for the questionnaire to be piloted.

The questionnaire was pilot-tested among 50 students who used the TMM program for 40 hours during the summer of the Academic Year 2015. To ensure that the responses were reliable, the items were subjected to an analysis with a SPSS program for its Cronbach alpha co-efficient value. The construct on learners' perception of usefulness and ease of use of TMM had a Cronbach alpha co-efficient value of .92 and .81 respectively. The construct on learners' practices had a Cronbach alpha co-efficient value of .63. According to DeVellis (2003), these values considered an adequate value for internal reliability of a scale. The researcher proceeded to collect data for the main study. 


\section{Data Collection Procedures}

\section{Implementation of Questionnaires}

For the questionnaire, the researcher distributed 350 questionnaires to the targeted sample who fell within the population through the following processes: (1) Snow balling: This method was used because the all of the potential participants were hard to find. The researcher identified some participants from different faculties and asked them to distribute the questionnaires to the other subjects (Heckathorn, 1997). (2) Classroom distribution at the selected faculties: The researcher used this strategy in order to get a high response. The researcher sought permission from instructors from selected faculties for the distribution and collection of the questionnaire. The researcher used this approach to randomly select participants to ensure that each first year user of the program stood the chance of been chosen. These approaches to data collection were used for a high response rate. The whole data collection process took more than two weeks.

\section{Focus Group Interview}

The participants for the interview were purposively selected based on their responses to the survey. This was done to ensure heterogeneity in students from different proficiency levels and faculties were selected. The interviewee for the semi-structured focused group interview were invited through phone calls and classroom announcement. For the phone calls, the selection was randomly made based from responses of the survey. The announcement was made at selected faculties that took part in the survey. The researcher sought permission from the lecturers in charge at the various faculties. In the end, 10 students showed up for the interview.

The interview was conducted in Thai with the help of a proficient bilingual moderator. The moderator, who was already knowledgeable about the research, was guided on how to conduct the interview. The items developed for the interview served as a guide for the moderator during the process. The interviewer sought the approval from the interviewees for a video recording. The interviewees were assured that it was for transcription and translation purposes and under no circumstance will their identity be revealed. They were given the pseudonyms, "Participant 1 to $10^{\prime \prime}$. The participants could answer the questions at their free will. The interview lasted between 30 to 45 minutes.

\section{Data Analysis}

Three hundred and forty (340) questionnaires were returned for analysis. The researcher ran a descriptive statistical analysis (means and standard deviation) of the items of the questionnaire with a SPSS program and interpreted the findings. The statistical calculation of the interval for the four and five Likert scale was interpreted accordingly.

The responses from the interview were analyzed by the researcher and the bilingual expert. The bilingual expert listened to and transcribed the responses twice from the recorded video tape. The second transcription was done to ensure consistency with the first transcripts. Both transcripts were compared to make sure it was reliable and credible. It was then translated into 
English for its content to be analyzed. After the analysis of the content, the common themes and patterns in the responses were categorized according to constructs under study.

In order to substantiate our findings arrived at from the simultaneous data collection (survey and semi-structured focused group interview), the researcher proceeded to triangulate the findings with responses from the survey to identify common patterns emanated from both instruments. This parallel analysis of the data aimed at deepening understanding on learners' perceptions and practices with the Tell Me More program.

\section{Findings}

The findings of the study were presented according to research questions. It includes a parallel analysis of results from the survey and the semi-structured focused group interview

\section{What Were Learners' Perception of the Usefulness and Ease of Use of the Tell Me More Program?}

In Table 3, the result indicated that the learners highly perceived TMM ( $\bar{X}=3.53)$ of the usefulness for practicing and improving their listening skills. This suggested that listening activities in the program gave learners avenues to improve their listening through planned activities. A participant stated the usefulness of the listening part as follows:

The Tell Me More program helped me improve my listening skills. The native speakers speak in all the activities so I can listen to the activities at the standard level.

They also moderately perceived ( $\bar{X}=3.31)$ that TMM's usefulness for practicing speaking and pronunciation. This means that the program gave learners the chance to mimic words and phrases that they may by shy or not confident enough to say under normal circumstances. They are as follows:

The Tell Me More program is good for practicing my speaking and pronunciation skills since I do not have other English language speakers to practice speaking English. However, I cannot engage in a conversation with it.

Additionally, the learners' perception of TMM's usefulness for reading was high at $\bar{X}=3.52$. This finding shows how learners could identify word, phrases and finally string them into sentences and read them to improve their reading. An interviewee remarked how useful and challenging this part of the program was:

The reading texts in the program are useful, it is interesting and challenging at the same time because the words in the passages are sometimes at my level or beyond my current level of knowledge. However, I sometimes do not understand the context of the passage.

However, the writing aspect had a below moderate mean score of $\bar{X}=3.21$. Like learners' perception with the writing aspect of TMM, grammar aspect had a similar moderate score of $\bar{X}=3.34$. What could account for this is learners' inability to apply the grammatical knowledge to 
form appropriate sentences. They perceived that the grammar explanation as either inadequate or not clear and straightforward enough. Below is the statement:

The program is useful for improving other English language skills but not writing and grammar knowledge because there are no explanations given to the wrong sentences I write. I do not know which part of the sentence is ungrammatical so I become confused.

Furthermore, the vocabulary aspect of the program had the highest mean score of $\bar{X}=3.70$. This indicated that the learners perceived the program more useful for vocabulary learning. The excerpt confirms this:

There are interesting ways I can use to improve my vocabulary in the program. I enjoy it anytime I use the crossword puzzle, which is a quick way for me to learn more vocabulary.

Overall, the items recorded an overall moderate mean of $\bar{X}=3.42$. This shows that the learners perceived TMM moderately useful for improving their English language proficiency.

Table 2. Perceived usefulness of Tell Me More (Mean, Standard deviation)

\begin{tabular}{lllll}
\hline & Perception Of Usefulness & $\mathbf{X}$ & S.D & Interpretations \\
\hline 1. & TMM helps me improve my listening skill. & 3.53 & .803 & High \\
\hline 2. & $\begin{array}{l}\text { TMM helps me improve my speaking and } \\
\text { pronunciation skill. }\end{array}$ & 3.31 & .880 & Medium \\
\hline 3. & TMM helps me improve my reading skill. & 3.52 & .829 & High \\
\hline 4. & TMM helps me improve my writing skill. & 3.21 & .859 & Medium \\
\hline 5. & $\begin{array}{l}\text { TMM helps me improve my grammar } \\
\text { knowledge. }\end{array}$ & 3.34 & .859 & Medium \\
\hline 6. & $\begin{array}{l}\text { The activities in TMM are useful for } \\
\text { vocabulary learning. }\end{array}$ & 3.70 & 1.769 & High \\
\hline I. have improved my overall English language & 3.42 & .822 & Medium \\
& proficiency. & & & \\
\hline
\end{tabular}

\section{Ease of Use}

The moderate mean and standard deviation for this item was $\bar{X}=3.35$ means that TMM could be used anytime for language learning; however, learners may encounter some internet connection problems. In relation to this, one participant said:

I like the Tell Me More program because it is suitable and enjoyable for online learning. The content is also easy to understand and I can use it anytime as I desire but not when the internet connection is down.

In relation to how easy it is to use TMM, the moderate mean and standard deviation of $\bar{X}=3.34$ indicate that the learners may have encountered problems ranging from internet connection, 
their English language ability and the learning environment of the program. A participant remarked:

The program is good and easy for learning English especially for me as a beginner because it contains tips and tricks that helped me improve my English language skill especially my pronunciation. However, if the internet connection is poor it makes moving to the next lesson difficult.

Table 3. Perceived Ease of Use of Tell Me More (Mean, Standard deviation)

\begin{tabular}{llccl}
\hline & Perception Of Ease Of Use & X & S.D & Interpretations \\
\hline 8. & $\begin{array}{l}\text { It is easy for me to learn English with TMM } \\
\text { anytime. }\end{array}$ & 3.35 & .977 & Medium \\
\hline 9. & The learning activities in TMM are easy to do. & 3.34 & .832 & Medium \\
\hline 10. & $\begin{array}{l}\text { The directions in TMM are easy to understand } \\
\text { and follow. }\end{array}$ & 3.54 & .866 & High \\
\hline 11. & There are many ways to answer the questions. & 3.33 & .808 & Medium \\
\hline
\end{tabular}

The learners perceived that the navigation in the program was not difficult to follow. This may be because the learners were technologically proficient to navigate through the program. The high mean $\bar{X}=3.54$ and standard deviation confirms this. An interviewee commented:

What makes the program easy to use is that I can skip to any activity of my choice since I am not obliged to follow the activities systematically. I sometimes select an activity I like if I find the current one uninteresting, difficult, or too easy to do.

The learners perceived that there were several ways to answer the questions in the program. The mean deviation for this item was $\bar{X}=3.33$. What could explain this divided perception is that learners may have looked at the answers keys for an easy way out. A participant said:

For me, apart from doing the activities on my own, I sometimes look at the answer keys. So aside my own effort, I get help from the program and that makes it easy for me to use the program.

\section{What Were Learners' Practices When Using the Tell Me More Program?}

The findings indicated the learners read the instructions before they begun doing the activity. The high mean score of $\bar{x}=2.73$ confirms this. This indicates learners' positive instructions reading attitude habits. Additionally, the findings showed that the learners kept trying before I got the answer to a question right. The high mean score $(\bar{x}=2.72)$ in his category shows the effort learners' often made when they faced tasks that were challenging or beyond their level of proficiency. The excerpt confirms this:

I had to put in effort to answer the questions in the program correctly to make me feel proud of myself. 
However, the high mean score $(\bar{x}=2.65)$ for the item "I skip to other activities when I face challenges" shows learners inconsistent practices. The learners often did that and it contradicts with learners' report that they kept trying until they got the right answer to a task. Below is an excerpt by a participant:

When I use the program, I have to think hard before I can complete the activities. I keep trying though it is less fun, it helps me improve my English. I can see about $70 \%$ improvement in my English language skills.

The findings further revealed that the learners often consulted the answer key for answers when they get an answer in an activity wrong. The high mean score $(\bar{X}=2.54)$ attests to this. This finding supports learners' inconsistency and suggest that learners may not have made enough effort in getting the answers right before proceeding to the next task. This may be due to the difficulty level of the task or learners English language ability. Two respondents said:

I have no time to waste on one question; I skip to a new activity when I find the current on challenging for me. I sometimes also go to the answer key for solutions.

Another respondent opined:

I do not want spend time on the program without gaining any knowledge. I have to keep trying until I get the correct. To gain more knowledge, I find answers from other sources other than the answer key to do the task.

Furthermore, the low mean score $\bar{X}=1.87$ showed that the learners sometimes went straight to the answer keys for solutions. This finding further shows learners inconsistent practices. A respondent said:

There is too much complication in the program so to make it easy and fast for me, I go straight to the any keys for solutions.

In relation to learners' practices of leaving the program on to count the time, the low mean score $(\bar{X}=2.45)$ suggests that the learners sometimes left the program on to count the time probably because they were graded based on the number of hours spent on the program. Below are statements from the participants:

I leave the program on to count the time because most of the time I finish doing the activities in the program before the required number of hours. The only way to get the grade is to leave the program on since the hour is still needed.

Another participant remarked:

I do not focus on the hours of use. I focus on the content but if I continue to do that, I will end up not fulfilling the minimum hours. Therefore, I leave it on. I think there is no need to focus on the hours but the correctly answered questions.

With regard to learners making others do the activities for them, the very low mean score $(\bar{X}=1.47)$ suggests that majority of the students showed a great sense of responsibility by taking charge of the learning process. One participant said: 
I cannot rely on anybody to do the activities in the program for you because everybody is using the program and is responsible for it at the end of the semester. I had to put in effort to answer the questions in the program correctly to make me feel good.

Table 4. Learners Practices with Tell Me More (Mean, Standard Deviation, Frequency \& Percentage)

The results of the low mean score $(\bar{X}=2.24)$ for the item "I find help from other materials or sources" means that learners resorted to other forms of materials in addition to the content of

\begin{tabular}{|c|c|c|c|c|}
\hline & Practices & $\mathbf{x}$ & S.D & Interpretations \\
\hline 12. & $\begin{array}{l}\text { I read the directions for every activity } \\
\text { before I start to practice. }\end{array}$ & 2.73 & .825 & High \\
\hline 13. & $\begin{array}{l}\text { I keep trying an activity until I get the } \\
\text { correct answer. }\end{array}$ & 2.72 & .803 & High \\
\hline 14. & $\begin{array}{l}\text { I skip to new activities when I face } \\
\text { difficulties. }\end{array}$ & 2.65 & .885 & High \\
\hline 15. & $\begin{array}{l}\text { I look at the answers in the answer key } \\
\text { when I answer a question incorrectly. }\end{array}$ & 2.54 & .863 & High \\
\hline 16. & $\begin{array}{l}\text { I go to the answer key immediately to do } \\
\text { the activities. }\end{array}$ & 1.87 & .812 & Low \\
\hline 17. & I leave the program on to count the time. & 2.45 & .879 & Medium \\
\hline 18. & I ask someone to do the activities for me. & 1.47 & .777 & Very low \\
\hline 19. & $\begin{array}{l}\text { I find help from other materials (google } \\
\text { translate, dictionary, google). }\end{array}$ & 2.24 & .863 & Low \\
\hline
\end{tabular}

the TMM program. This item further confirms learners' actions of trying until they got the answer correct. Learners may have kept trying by resorting to other materials. Two participants pointed out the following:

The way the program is set up encourages me to seek help from other sources. Sometimes there are no explanations further to where and why I got an answer wrong. This raises motivation to search further for help to know where I am completely wrong.

Another participant said:

I do not know how to find help from other internet sources; I just skip when the activity it is higher than my level of ability or when I cannot use the activity in my daily life. Moreover, I look at the answers in the answer key.

\section{Were There Any Relationships between Learners' Perceptions and Practices with TMM?}

The Pearson correlation analysis revealed a relationship between perceived ease of use and perceive usefulness of TMM. Perceived ease of use had a positively moderate correlation with perceived usefulness $(r=.617, p<.01)$. This means that the more learners perceived TMM useful, 
the more they perceived it easy to use. However, there was no correlation between perceived ease of use and learners practices $(r=.052, p>.05)$. The analysis further revealed no correlations between perceived usefulness and practices with TMM $(r=.103, p>.05)$.

Table 5.Correlation between Learners' Perception and Practices

\begin{tabular}{llll}
\hline Constructs & Ease of use & Usefulness & Practices \\
\hline Ease of use & 1 & $.617^{* *}$ & $.052^{*}$ \\
\hline Usefulness & & 1 & $.103^{*}$ \\
\hline Practices & & & 1 \\
\hline
\end{tabular}

**significant at the 0.01 level (1-tailed).

*significant at the 0.05 level (1-tailed).

\section{What Was the Effect of Tell Me More on the Language Achievement of Learners in Different Proficiency Groups?}

The researcher examined the data of 2,137 students for any improvement in the performance of the students from four proficiency levels (Beginner, intermediate, intermediate+ and advanced) in the placement, progress and achievement tests. While both the placement and progress tests were scored 10 points each and was at a similar level of difficulty, the achievement test was scored out of 800 points and was at a higher level of difficulty. All the tests were incorporated in the program.

Since the placement, progress and achievement tests were scored differently, a z score analysis was done to standardize and compare the scores of the different sets of data of the various proficiency levels. Table 5 reports the comparison of the mean and $z$ score analysis for the Placement and Achievement tests scores for each proficiency level in were as follows.

For the beginners, the mean and $z$ score were: the placement test $(\bar{x}=2.39, z=-0.96)$, progress test $(\bar{x}=3, z=-0.72)$ and achievement test $(\bar{x}=285.89, z=-0.59)$. The mean and $z$ score for the intermediate level in all the three tests were as follows: placement test $(\bar{x}=3.86, z=-0.20)$, progress test $(\bar{x}=3.89, z=-0.29)$ and achievement test $(\bar{x}=306.66, z=-0.38)$. For the intermediate+ level, the mean and $z$ score were: the placement test $(\bar{x}=6.22, z=1.01)$, progress test $(\bar{x}=6.34, z=0.90)$ and achievement test $(\bar{x}=419.38, z=0.77)$. The advanced proficiency level students had means and $z$ scores as follows: placement test $(\bar{x}=8.62, z=2.23)$, progress test $(\bar{x}=$ $8.53, \mathrm{z}=1.97)$ and achievement test $(\overline{\mathrm{x}}=566.42, \mathrm{z}=0.77)$.

To know the impact of TMM on learners' achievement, a further analysis of the differences between the means of the $z$ scores of the placement and achievement test scores ( $Z$ diff 6-4) revealed a $z$ difference as follows beginner $(z=0.37)$, intermediate $(z=-0.18)$, intermediate $+(-$ $0.24)$ and advanced (0.04). This means that the beginner and advanced group had an increase in their achievement while the intermediate+ and intermediate group had no improvement in their performance. 
Table 6. Learners' Achievement (Means, Standard Deviations and z scores of the tests)

\begin{tabular}{lccccc}
\hline Proficiency levels & $\begin{array}{c}\text { Beginner } \\
(\mathbf{n = 6 7 6 )}\end{array}$ & $\begin{array}{c}\text { Intermediate } \\
(\mathbf{n}=\mathbf{8 4 6})\end{array}$ & $\begin{array}{c}\text { Intermediate+ } \\
(\mathbf{n}=\mathbf{4 5 0})\end{array}$ & $\begin{array}{c}\text { Advanced } \\
(\mathbf{n}=\mathbf{1 6 5})\end{array}$ & $\begin{array}{c}\text { Total } \\
(\mathbf{n}=\mathbf{2 1 3 7})\end{array}$ \\
\hline \multicolumn{1}{c}{ Tests } & $\overline{\mathbf{x}}$ & $\overline{\mathbf{x}}$ & $\overline{\mathbf{x}}$ & $\overline{\mathbf{x}}$ & $\overline{\mathbf{x}}$ \\
\hline 1. Placement Test & 2.39 & 3.86 & 6.22 & 8.62 & 4.26 \\
\hline 2. Progress Test & 3.00 & 3.89 & 6.34 & 8.53 & 4.48 \\
\hline 3. Achievement Test & 285.89 & 306.66 & 419.38 & 566.42 & 343.85 \\
\hline 4. zPlacement Test & -0.96 & -0.20 & 1.01 & 2.23 & 0.00 \\
\hline 5. zProgress Test & -0.72 & -0.29 & 0.90 & 1.97 & 0.00 \\
\hline 6. zAchievement Test & -0.59 & -0.38 & 0.77 & 2.27 & 0.00 \\
\hline 7. zDiff (6-4) & 0.37 & -0.18 & -0.24 & 0.04 & 0.00 \\
\hline
\end{tabular}

\section{Discussion}

\section{What Were Learners' Perception of the Usefulness and Ease of Use of the Tell Me More Program?}

The learners perceived that TMM was useful for improving vocabulary, listening and reading skills respectively (Table 3 ). This is probably because there are enough vocabulary, reading and listening activities in the program. The enormous amount of vocabulary in the program structured around crosswords, dictation and gap filling could explains why this item had the highest mean. Vocabulary plays an important role in learning how to read. This confirmed the studies by Kamil (2004) and Beck and McKeown, (2007) that as learners begin to read, they link the vocabulary they have learned to the text they read, this eventually influence their listening and speaking skill.

However, inadequate instant feedback, limited interactions and little connection among the speech recognition, pronunciation, grammar and writing aspects may have accounted for a moderate perception of usefulness. Their report that the program marks every part of the sentence they write as wrong coupled with few grammatical explanation to explain why shows that the program still needs to be improved to stimulate learners for better write-ups through the provision of adequate grammatical explanation. This finding further confirms Espinosa (2010) and Gyamfi and Sukseemuang (2017) study on TMM but partially in line with the study conducted in Malaysia by Yunus et al. (2010) not in line with Perez (2014) research. The different research context may account for difference in research findings for the later studies and the current study.

Furthermore, as shy and unmotivated Thai learners may be, the TMM environment broke those barriers thereby making them as ease to study. TMM learning environment was nonthreatening. Due to this student may feel at ease to learn by accepting and correcting any errors and mistakes they make in the learning process. Even though, the study by Wan Irham and Shafinah (2006) supports this finding, learners in different learning context react differently to their use of educational technologies for language learning. Hence, like other research on tutorial CALL products, the results of this study indicate that users have different perceptions of 
Tell Me More. Moreover, some variables such as learners' motivation and attitude have been found to have an effect on their perceptions of and practices with tutorial CALL programs (Ushioda, 2005).

\section{What Were Learners' Practices with the Tell Me More Program}

\section{Multitasking}

Since self-study does not imply learning in isolation, the learners reported to have multitasked by sometimes and often consulting other sources such as Google Translate, online dictionaries, and other supplementary materials for better understanding (Table 5). The learners may have also multitasked because they may have found other sources of information as relevant to their unconscious acquisition of language. This shows the freedom of choice or flexibility the online learning program gave the learners. Hence, the TMM program eased and enabled learning practices beyond its immediate online learning environment. This finding confirmed Jarvis (2012) study that EFL learners make use of other computer-based resources to aid their conscious learning of English language.

\section{Inconsistent Self-study Practices}

The learners demonstrated significant effort by first exhibiting good reading practices and doing the activities in the program on their own. However, there were some inconsistencies in their practices. They skipped when they faced tasks that were challenging or beyond their ability. In addition, their practices of looking at the answers before doing the activities and immediately after trying once obviously undermined the efficacy of the program (Table 3 ). This does reflect learners' moderate perception of the usefulness of the program. These unstable learning practices signify learners' perception of the ease in using programs that contain in-built answers. These behaviors may not help instructors know the real impact of the program on students English language ability. These findings support Waemusa, Srichai and Wongphasukchote (2008) study that learners may demonstrate unstable learning practices in their online self-study learning process. However, this aspect of self-study is difficult to control because of the lack of external monitoring. It further confirmed Sukseemuang (2009) findings and recommendation that though learners may favor self-directed learning, they may however need some form of control to engage in the right learning practices.

\section{Time of Use}

The finding on the hours of use partially confirmed by Glisan, Dudt and Howe (1998) study that time of use is beneficial for online learning. In this study, the learners' sometimes and often left the program on to count the time (Table 5). One reason that may have accounted for this practice as revealed in the focused group interview was that assessment of the course for which the Tell Me More program was a part of was based on the number of hours spent on the program. Hence, students may have focused on fulfilling the time requirement as opposed to learning the content in the program. 
Additionally, what holds true is that learners may have finished doing the assignments in the program before the required time. Hence their behavior of leaving the program on to fulfill the time requirement. The findings on the time further signifies that learning goals had the capacity to influence students' practices. Therefore, to demonstrate a workable time management strategy, assessment of learning progress in autonomous educational technologies should not be solely based on time. There could be innovative ways to assess learning progress that also focuses on content.

\section{Was There Any Relationships between Learners' Perceptions and Practices with TMM?}

The findings further revealed that perceived ease of TMM use had a significant and positive moderate correlation with perceived usefulness (Table 6). What could probably account for this correlation is because of the learners' technological proficiency. The use of the program required only basic knowledge of technology. Hence, the learners could easily use the program after getting minimal training from the instructors. Additionally, the convenience and accessibility to use the program anywhere and anytime may account for the moderate but positive correlation between TMM ease of use and usefulness. This finding is in accordance with previous studies conducted on online learning program in which perceived ease of use had a strong correlation with perceived usefulness and attitude towards use (Chang et al., 2012; Park, 2009).

The last issue worth discussing has to do with the lack of correlation among learners' practices and perception. This means that the learners found TMM useful and easy to use but did not use the appropriate learning practices. Although there was no meaningful correlation among learners' practices and perceptions, it should not be overlooked. Overlooking this may have negative consequences on how learners use TMM to enhance their English language ability. It is therefore necessary for stakeholders and instructors to train learners adequately by equipping them with skills and knowledge on how to use TMM appropriately. This in turn will positively influence learners' perceptions and practices for successful learning outcomes.

\section{What Effect Did Tell Me More Have on the Language Achievement of Learner in Different Proficiency Groups?}

A comparison between the $z$ scores on the placement and achievement tests in Table 5 indicated an improvement in the level of English for the beginner and intermediate levels. The $z$ scores difference between the placement and achievement tests for three proficiency levels beginner $(z=0.37)$ and intermediate $(z=-0.18)$ shows an improvement in the performance of learners. It could be deduced that learners from these proficiency levels perceived TMM highly useful and therefore engaged in appropriate learning practices.

On the other hand, the TMM did not have any impact on students at the intermediate $+(z=-0.24)$ and advanced $(z=0.04)$ English proficiency levels. Though the students at this level had high mean and $z$ scores in their achievement test it showed no improvement. Though this result may be due to the perceptions this category of learners had about TMM, what may equally hold true is that the content of the program may not have been challenging for learners at this level. 
The results therefore suggest that the TMM program is effective for students at the beginner and advanced levels. This signifies that the TMM program is more suitable for students with a lower in English because they may perceive it highly useful for improving their language. This confirms the findings in Nowaczkyk (1998) and Lin (2014), that the use of technology that incorporates concepts and organizes information have a positive impact on students with low level of proficiency in language learning. Additionally, the beginner learners' may have highly perceived TMM usefulness and ease of use for learning English.

\section{Conclusions and Recommendations}

Although the TMM program offered a greater opportunity of inclusion at all proficiency levels, it must be admitted that language learning is far from simple especially for EFL students. As indicated in the study, two factors come to play to ensure that learning technologies get the expected impact. Below are some useful recommendations for using TMM.

\section{Assessment of Learners' Achievement}

The study recommends that users of the program should not only be evaluated based on the hours of use. In other words, time of use should not be the sole indicator of learning progress and achievement in an online self-study setting. In addition to hours of use, learners could be evaluated based on a specific score in an achievement test to help know the effect of the program on their English language skills. Moreover, quantifiable ways such as incorporating contents of online learning programs in written tests could be used to supplement assessment to measure learning progress.

\section{Enhancing Multitasking and Online Learning Skills}

In relation to learners' multitasking practices, they could be introduced to specific websites to access to seek assistance when they face challenges with the content of the program. This will help guide the learning process and decrease the practice of looking at the answers before doing the activities. Learners could therefore keep track and assess their learning process to become successful online learners.

\section{Improving Consistency Online Learning Practices}

For learners to engage in effective and consistent online learning practices, it is necessary to train learners comprehensively at the beginning of their self-study with the program in order to familiarize them with the new method of learning online. When this is done, learners would have a clear sense of direction on how to set goals, select strategies and control their learning process. 


\section{Recommendation for Further Studies}

Further studies on TMM could focus on its effectiveness in relation to improving the specific skills of learners (Reading, Writing, Speaking, and Listening) across different proficiency levels in a variety of educational settings.

\section{Acknowledgements}

This work was supported by the Higher Education Research Promotion and Thailand's Education Hub for Southern Region of ASEAN countries Project Office of the Higher Education Commission.

\section{References}

Alotaibi, K. N. (2015). The learning environment as a mediating variable between self-directed learning readiness and academic performance of a sample of Saudi nursing and medical emergency students. Nurse Education Today, 36, 249-254.

Artelt, C., Baumert, J., Julius-McElvany, N., \& Peschar, J. (2003). Learners for life: Student approaches to learning. Results from PISA 2000. Paris: Organization for Economic Cooperation and Development.

Barr, D. (2016). Students and ICT: An analysis of student reaction to the use of computer technology in language learning. IALLT Journal of Language Learning Technologies, 36(2), 19-38.

Beck, I. L. \& McKeown, M. G., (2007). Increasing young low-income children's oral vocabulary repertoires through rich and focused instruction. Elementary School Journal, 107(3), 251-271.

Chang, C., Yan, C., \& Tseng, J. (2012). Perceived convenience in an extended technology acceptance model: Mobile technology and English learning for college students. Australasian Journal of Educational Technology, 28 (5), 809-826.

Coklar, A. N. (2012). Evaluations of students on Facebook as an educational environment. Turkish Online Journal of Qualitative Inquiry, 3(2), 42-53.

Creswell, J. W., Clark. P., V. L., Gutmann, M. L., \& Hanson, W. E. (2003). Advanced mixed methods research designs. In A. Tashakkori and C. Teddlie (Eds.), Handbook of mixed methods in social and behavioral research (pp.209-240). Thousand Oaks, CA: Sage.

Davis, F. D. (1989). Perceived usefulness, perceived ease of use, and user acceptance of information technology. MIS Quarterly, 13(3), 319-340.

DeVellis, R. F. (2003). Scale development: Theory and applications. Thousand Oaks, CA: Sage.

Espinosa, B (2013), Learning English using Tell Me More: Perspectives of university teaching staff as users of the online application. Retrieved on 1 May 2017 from https://www.researchgate.net/publication/278171803Learning

Glisan, G., Dudt, K., \& Howe, M. (1998). Teaching Spanish through distance education: Implications of a pilot study. Foreign Language Annals, 31, 48-66. 
Godwin-Jones, R. (2010). Emerging technologies tools and trends in self-paced language instruction. Language Learning \& Technology, 11(2), 10-17. Retrieved on 1 May 2017 from http://lt.msu.edu/vol11num2/ emerging/default.html.

Gyamfi, G. \& Sukseemuang, P. (2017). Factors affecting EFL learners' use of the computer language learning program Tell Me More. International Journal of Instructional Technology and Distance Learning, 14(2), 69-79.

Heckathorn, D. (1997). Respondent-driven sampling: A new approach to the study of hidden populations. Social Problems, 44(2), 174-199.

Jarvis, H. (2013). Computers and learner autonomy: Trends and issues. British Council ELT Research Papers, 1, 387-409.

Kamil, M. L. (2004). Vocabulary and comprehension instruction: Summary and implications of the National Reading Panel findings. In P. McCardle and V. Chhabra (Eds.). The voice of evidence in reading research. Baltimore, MD: Paul H. Brookes.

Kennedy, G., Judd, T., Churchward, A., Gray, K., \& Krause, K.-L. (2008). First year students' experiences with technology: Are they really digital natives. Australasian Journal of Educational Technology, 24(1), 108-122. doi:http://dx.doi.org/10.14742/ajet.1233

Knowles, M. (1975). Self directed learning. Oxford, England: Gulf Publishing.

Krejcie, R.V. \& Morgan, D.W. (1970) Determining Sample Size for Research Activities. Educational and Psychological Measurement, 30, 607-610.

Kuama, S. \& Intharaksa, U. (2016) University students' perceptions of an online English language course. Proceedings of ICHiss 2016: $8^{\text {th }}$ International Conference on Humanities and Social Sciences. National Defense University of Malaysia. (pp 226-336). Selangor, Malaysia.

Kvavik, R. B. (2005). Convenience, communications, and control: How students use technology. Educating the Net Generation, 1, 7.1-7.20.

Lafford, B. A. (2004). Review of Tell Me More Spanish. Language Learning \& Technology, 8 (3), 21-34. Retrieved on 1 May 2017 from http://Itt.msu.edu/vol8num3/review1/default. html.

Levy, M. (1997) CALL: Context and conceptualization. Modern Language Journal, 79(4), 457476.

Lin, H. (2014). Establishing an empirical link between computer mediated communication (CMC) and SLA: A meta-analysis of the research. Language Learning \& Technology, 18(3), 120-147

Nielson, K. (2011). Self-study with language learning software in the workplace: What happens? Language Learning \& Technology, 15(3), 110-129. Retrieved on 1 May 2017 from http://ltt.msu.edu/issues/october2011/nielson.pdf.

Nowaczyk, R. (1998). Student perception of multimedia in the undergraduate classroom. International Journal of Instructional Media, 25, 367-368.

Perez, A. (2014). Effectiveness of Tell Me More in enhancing communication skills. Asia Pacific Journal of Multidisciplinary Research, 2(6), 164-172.

Reeser, T. W. (2002). CALICO Software Review. Tell Me More-French. CALICO Journal, 19(2), 419-428. 
Spanjers, D. M., Burns, M. K., \& Wagner, A. R (2008). Systematic direct observation of time on task as a measure of student engagement. Assessments for Effective Intervention, 33, 120

Sukseemuang, P. (2009). Self-directedness and academic success of students enrolling in hybrid and traditional courses (Unpublished doctoral dissertation). Retrieved on 1 May 2017 from http://gateway.proquest.com/open.

Ushioda, E. (2005). The role of students' attitudes and motivation in second language learning in online language courses. CALICO Journal, 23(1), 49-78.

Ulitsky, H. (2000). Language learner strategies with technology. Journal of Educational Computing Research, 22(3), 285-322.

Van Zanten R., Somogyi, S., \& Curro, G. (2012). Purpose and preference in educational podcasting. British Journal of Educational Technology, 43(1), 130-138. doi:10.1111/j.1467-8535.2010.01153.

Venkatesh, V., Croteau, A.-M., \& Rabah, J. (2014). Perceptions of effectiveness of instructional uses of technology in higher education in an era of Web 2.0. Paper presented at the 47th Hawaii International Conference on System Sciences. Waikoloa, HI.

Waemusa, S., Srichai, H, \& Wongphasukchote, K. (2008). A study of Thai learners' responsibility in learning a foreign language. Retrieved on 1 May 2017 from http://kb.psu.ac.th/psukb/ handle/ 2010/8003.

Wan Irham, I. \& Shafinah, S. (2006). Utilizing ESL websites as learning tool to learn. In M. K. Kabilan et al. (Eds.).Online teaching and learning in ELT. Penang: Penerbit USM. 80-92.

Weston, M.E. \& Bain, A. (2010). The end of techno-critique: The naked truth about 1:1 laptop initiatives and educational change. Journal of Technology, Learning and Assessment, 9(6). Retrieved on 1 May 2017 from http://www.jtla.com.

Willis, J. (2006). Research-based strategies to ignite student learning: Memory, learning, and test taking success. Retrieved on 1 May 2017 from http://www.ascd.org/publications/ book/197006/chapters/Memory.

Yunus, M., Hasim, H., Embi, M. A., \& Lubis, M. A. (2010). The utilization of ICT in the teaching and learning of English: 'Tell Me More'. Procedia. Social and Behavioural Sciences, 9, 685-691.

Yunus, M., Hasim, H., Jusoff, K., Nordin, N. M., Yasin, R. M., \& \& Rahman, S. (2010). ESL lectures' voices on Tell Me More. Studies in Literature and Language, 1(1), 69-84.

Correspondence: George Gyamfi, Assistant Professor, Department of Languages and Applied Linguistics, Faculty of Liberal Arts, Prince of Songkla University, Hat-Yai, Thailand. 